\title{
Multiple Modulation Strategy of Flying Capacitor DC/DC Converter
}

\author{
Pengcheng Li ${ }^{1, *(\mathbb{D})}$, Chunjiang Zhang ${ }^{2}$, Sanjeevikumar Padmanaban ${ }^{3, *(1)}$ \\ and Leonowicz Zbigniew 4 (D) \\ 1 Department of Electrical Engineering, Hebei University of Science and technology, \\ Shijiazhuang 050018, China \\ 2 Department of Electrical Engineering, Yanshan University, Qinhuangdao 066004, China \\ 3 Department of Energy Technology, Aalborg University, 6700 Esbjerg, Denmark \\ 4 Faculty of Electrical Engineering, Wroclaw University of Science and Technology, Wyb. Wyspianskiego 27, \\ 50370 Wroclaw, Poland \\ * $\quad$ Correspondence: lipengcheng@hebust.edu.cn (P.L.); san@et.aau.dk (S.P.); Tel.: +86-18630322865 (P.L.)
}

Received: 24 May 2019; Accepted: 5 July 2019; Published: 11 July 2019

\begin{abstract}
Flying-capacitor multiplexed modulation technology is suitable for bipolar DC microgrids with higher voltage levels and higher current levels. The module combination and corresponding modulation method can be flexibly selected according to the voltage level and capacity level. This paper proposes a bipolar bidirectional DC/DC converter and its interleaved-complementary modulation strategy that is suitable for bipolar DC microgrids. The converter consists of two flying-capacitor three-level bidirectional DC/DC converters that are interleaved in parallel $90^{\circ}$, and then cascaded with another module to form a symmetrical structure of the upper and lower arms; the complementary modulation of the upper and lower half bridges constitutes an interleaved complementary multilevel bidirectional DC/DC converter. If the bidirectional converter needs to provide a stronger overcurrent capability, more bridge arms can be interleaved in parallel. Once $\mathrm{n}$ bridge arms are connected in parallel, the bridge arms should be interleaved $180^{\circ} / \mathrm{n}$ in parallel. In bipolar DC microgrids, the upper and lower arms should be complementarily modulated, and the input and output are isolated by the inductance. To solve the current difference, caused by the inconsistent parasitic, the voltage-current double closed-loop-control is used, and the dynamic response is faster during bidirectional operation. This paper proposes theoretical analysis and experiments that verify bipolar bidirectional DC/DC converter for high-power energy storage.
\end{abstract}

Keywords: bidirectional DC/DC converter (BDC); dual mode operation; current sharing; multiplexed modulation

\section{Introduction}

With the high penetration of intermittent energy, such as solar and wind [1-3], a power electronic interface for distributed energy storage is becoming increasingly attractive. The bidirectional DC/DC converter (BDC) is an important piece of equipment for distributed energy storage in DC microgrids, which helps to promote intermittent energy scale applications. The BDCs are widely used in DC microgrids, due to their simple structure, easy expansion, and transmission power being independent of transformers [4-7].

In particular, it plays a large irreplaceable role in the distributed energy storage of high voltage and high power. For BDCs, current research focuses on buck/boost two-level converters and control strategies for suppressing load disturbances [8,9]; however, switches are subject to low-voltages applications. The voltage and current stresses of the converter are relatively high, so a multilevel 
converter is required. A multiplexed multiphase and multilevel BDC is used for a wide range of voltage variations (voltage conversion level less than 10 times); different from multilevel converters required for a high-voltage DC transmission (voltage conversion level more than 10 times), relying on transformer boosting to achieve a higher level of voltage conversion [10-12]. The n-level structure of the multiplexed multilevel BDC reduce voltage stress only $1 / n$ of the high-side voltage; the $m$-phase of the multiplexed multiphase BDC reduce current stress only $1 / \mathrm{m}$ of the low-side current [13]. The multiphase and multilevel BDC adopts the interleaved phase modulation technology to improve the output current ripple frequency, reduce the filter capacitor ripple value in a DC microgrid [14-17].

When a battery is connected to a DC microgrid by a BDC, the BDC needs to have strong input and output impedance matching capability to keep the system stable. In particular, when the BDC operates in buck mode, the input impedance is large; when operating in boost mode, the input impedance is small; when operating in bidirectional mode, the impedance adjustment range is wider, and the response speed is faster, which is beneficial to the system stability [18].

H. L. Do. [19] proposed a soft-switching DC/DC converter with high voltage gain by a boost cell and a coupled inductor cell. Soft-switching characteristic reduces the switching loss of active power switches and increase the converter efficiency. However, the converter can only work in boost mode, and only $S_{2}$ and $D_{4}$ can achieve ZVS turn-on. The $S_{1}-D_{4}$ current stress is uneven, and $S_{1}$ has a higher current stress. In high-voltage and high-power distributed energy storage, it is necessary to consider the equalization and current sharing problems. X. S. Zhang et al. [20] proposed the idea of battery energy storage systems (BESSs) with integrated wind farms to stabilize the grid power. High-power $\mathrm{BDCs}$ are required to meet high power requirements.

R. Naderi et al. [21] proposed a dual flying capacitor active-neutral-point-clamped (DFC-ANPC) DC/AC inverter with a five-level modulation method that achieves soft switching and neutral point voltage balancing. More importantly, the five-level modulation method eliminates the transient voltage balancing issue by series-connected switches of $S_{5}$ and $S_{6}$ and decreases the switching loss. $F$. Mohammadi [22] discussed the configuration, operation and decoupled control mode of a VSC-HVDC. Compared to the pulse width modulation (PWM) strategies, the vector control method generates fewer voltage harmonics and allows to control the active and reactive power independently. The vector control method is used to control the VSC-HVDC system, which is based on transforming a 3- $\varphi$ system into a 2- $\varphi$ system by d-q frame. Droop control is easily affected by the line impedance and the frequency fluctuation of the power grid, which reduces the distribution accuracy of the active and reactive power. In the future, the bidirectional DC/DC converter (BDC) will be connected to a bipolar DC microgrid by droop control.

Reference [23] used a DC bus capacitor to provide a three-level state (buck/boost synchronous PWM modulation). However, the converter operates at high gain, and S1 is subjected to high current stress, which exacerbates the switching losses. In Reference [24], a two-level buck/boost converter is cascaded to form a three-level bidirectional DC/DC converter. However, the modulation method easily causes inconsistent duty ratios of the upper and lower half bridges to be inconsistent, thereby affecting the voltage equalization effect of the DC bus, and requires an additional voltage equalization control loop at boost mode, which increases the complexity of the control structure.

This paper proposes a multiplexed modulation technique of the flying capacitor DC/DC converter to meet the high-voltage and high-power requirements. The BDC has many advantages: (1) the bus capacitor voltage is easily stabilized by the midpoint potential balance control of the rear inverter circuit; (2) the BDC is easy to combine by the PWM sequence to achieve multiple modulations; (3) it is easy to design the control loop and suppress phase-to-phase circulation; and (4) the BDC has a strong fault tolerance ability, and failure of any one of the arms does not affect the operation of other arms. The BDC is suitable for battery energy storage systems in bipolar DC microgrids.

This paper organized as follows. The Flying capacitor type three-level DC/DC basic unit in Section 2. Multiple modulation techniques are presented in Section 3. Controller design in Section 4. Experimental verifications in Section 5. Some conclusions are given in Section 6. 


\section{Flying Capacitor Type Three-level DC-DC Basic Unit}

This paper proposes a bidirectional DC/DC converter (BDC) topology with multiplexed modulation strategy for a high-power system, as shown in Figure 1. The parallel operation improves the current capability of the BDC; the voltage level is increased in series operation; and the high-voltage and large-capacity characteristics are realized in series-parallel operation. The symbols and reference directions are indicated in the figure. The basic unit of the flying-capacitor-type three-level bidirectional DC/DC converter (3L_BDC) easily forms a bipolar BDC of high-voltage and high-current systems.

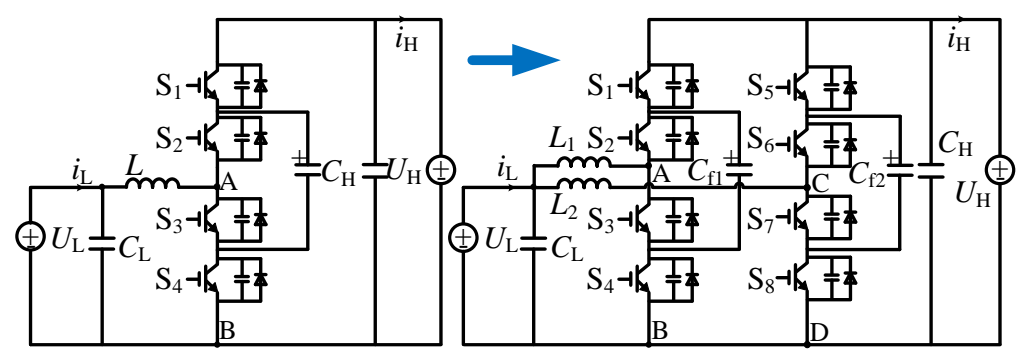

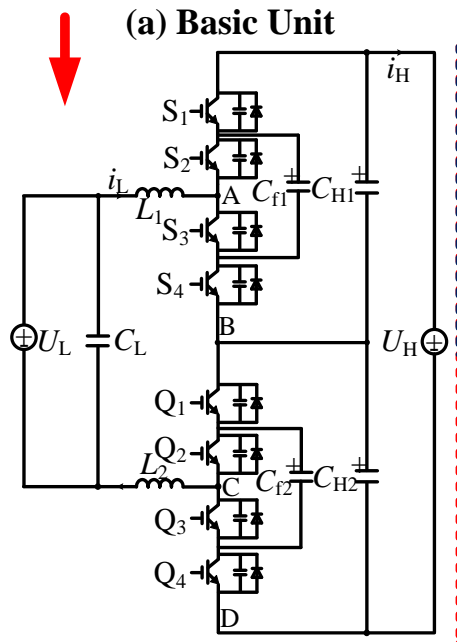

(c) Two arms series (b) Two arms parallel

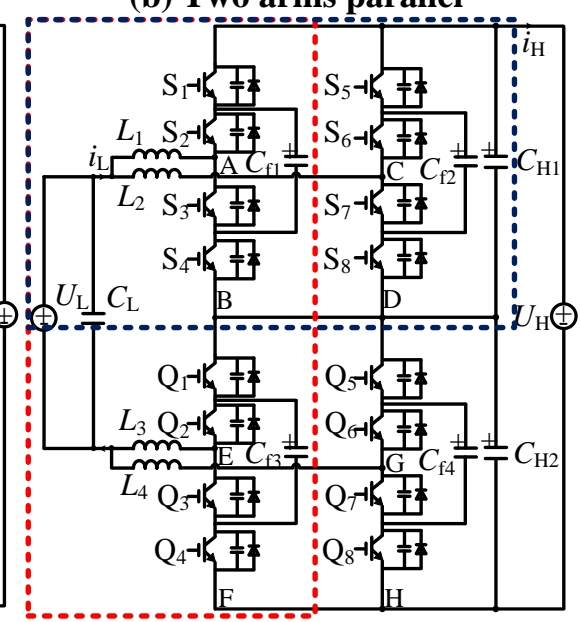

(d) Four arms mixed

Figure 1. The proposed bidirectional DC/DC converter. (a) Flying capacitor type three-level DC-DC basic unit. (b) Two basic units parallel. (c) Two basic units parallel. (d) Four basic units mixed.

In Figure $1 \mathrm{a}, U_{\mathrm{L}}$ is the input-side voltage, $U_{\mathrm{H}}$ is the DC bus side voltage, $C_{\mathrm{L}}$ is the battery-side capacitance, and $C_{H}$ is the DC bus side capacitance. The conduction time of $S_{3}$ and $S_{4}$ is defined as $T_{\text {on }}$ in the switching period $T_{\mathrm{s}}$, and the duty ratio is $D=T_{\mathrm{on}} / T_{\mathrm{s}}$. To facilitate the analysis, define the switch function as follows:

$$
M_{k}=\left\{\begin{array}{l}
00\left(\mathrm{~S}_{1}, \mathrm{~S}_{2} \mathrm{ON}, \mathrm{S}_{3}, \mathrm{~S}_{4} \mathrm{OFF}\right) \\
01\left(\mathrm{~S}_{2}, \mathrm{~S}_{4} \mathrm{ON}, \mathrm{S}_{1}, \mathrm{~S}_{3} \mathrm{OFF}\right) \\
10\left(\mathrm{~S}_{1}, \mathrm{~S}_{3} \mathrm{ON}, \mathrm{s}_{2}, \mathrm{~S}_{4} \mathrm{OFF}\right) \\
11\left(\mathrm{~S}_{3}, \mathrm{~S}_{4} \mathrm{ON}, \mathrm{S}_{1}, \mathrm{~S}_{2} \text { OFF }\right)
\end{array} .\right.
$$

The modal analysis is performed on the basic unit of the flying-capacitor-type three-level bidirectional DC/DC converter. The key waveform is shown in Figure 2. When the operating mode at $D>0.5$, the switching mode of $S_{3}$ and $S_{4}$ is only $01,10,11$, and not 00 . The voltage at the two points of $\mathrm{AB}$ is $0.5 U_{\mathrm{H}}$ or 0 ; at $D<0.5$, the switching mode of $S_{3}$ and $S_{4}$ is only $00,01,10$, and not 11 . The voltage of $\mathrm{AB}$ is $U_{\mathrm{H}}$ or $0.5 U_{\mathrm{H}}$. The inductive current flowing from the low-voltage side to the high-voltage side is defined as the positive direction. 


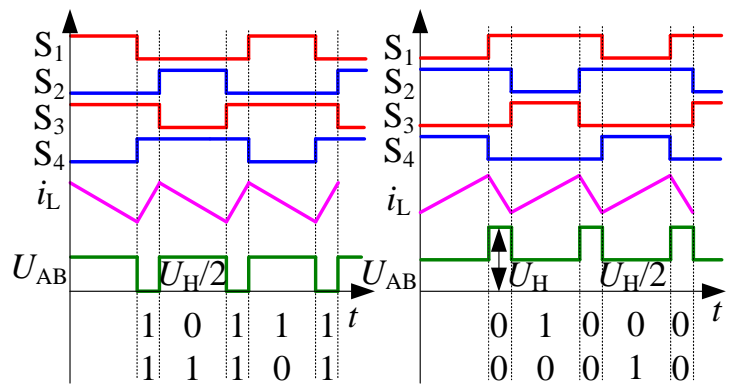

$\begin{array}{ll}\text { (a) } D>0.5 & \text { (b) } D<0.5\end{array}$

Figure 2. The main waveform of the basic unit. (a) Mode $D>0.5$. (b) Mode $D<0.5$.

2.1. Operational Modal Analysis D $>0.5$

During the switching cycle, there are three modes of 11,01 , and 10 for each arm.

1. Mode $M_{3}=11, S_{1}$ and $S_{2}$ are turned off, $S_{3}$ and $S_{4}$ are turned on, $S_{1}$ and $S_{2}$ voltage stress are $U_{\mathrm{H}} / 2$, the voltage of $\mathrm{AB}$ two-point is $U_{\mathrm{AB}}=0$, the inductor voltage across $L_{1}$ is $U_{\mathrm{L}}$, and $i_{\mathrm{L}}$ flows to the high-voltage side and linearly increases:

$$
\left\{\begin{array}{l}
\dot{i}_{\mathrm{L}}=-\frac{r_{\mathrm{L}}}{L} i_{\mathrm{L}}+\frac{1}{L} U_{\mathrm{L}} \\
\dot{U}_{\mathrm{H}}=-\frac{1}{R_{\mathrm{H}} C_{\mathrm{H}}} U_{\mathrm{H}} \\
\dot{U}_{\mathrm{f}}=0
\end{array}\right.
$$

2. Mode $M_{1}=01, S_{1}$ and $S_{3}$ turn off, $S_{2}$ and $S_{4}$ turn on, the $S_{1}$ and $S_{3}$ voltage stresses are $U_{\mathrm{H}} / 2$, the flying capacitor $C_{\mathrm{f} 1}$ charge according to the differential equation $C_{\mathrm{f} 1} \mathrm{~d} U_{\mathrm{f} 1} / \mathrm{d} t=I_{\mathrm{C}}$, that is $\Delta U_{\mathrm{f} 1}=t_{2} I_{\mathrm{c}} / C_{\mathrm{f} 1}=Q_{\mathrm{c}} / C_{\mathrm{f} 1}, U_{\mathrm{AB}}=U_{\mathrm{f} 1}=U_{\mathrm{H}} / 2$, the inductor $L_{1}$ is $U_{\mathrm{L}}-U_{\mathrm{AB}}<0$, the inductor current $i_{\mathrm{L}}$ decreases linearly, and the average inductor current is $I_{\mathrm{L}}=I_{\mathrm{C}}$.

$$
\left\{\begin{array}{l}
\dot{i}_{\mathrm{L}}=-\frac{r_{\mathrm{L}}}{L} i_{\mathrm{L}}+\frac{1}{L} U_{\mathrm{L}}-\frac{1}{L} U_{\mathrm{f}} \\
\dot{U}_{\mathrm{H}}=-\frac{1}{R_{\mathrm{H}} C_{\mathrm{H}}} U_{\mathrm{H}} \\
\dot{U}_{\mathrm{f}}=\frac{1}{C_{\mathrm{f}}} i_{\mathrm{L}}
\end{array} .\right.
$$

3. Mode $M_{3}=11, S_{1}$ and $S_{2}$ are turned off, $S_{3}$ and $S_{4}$ are turned on, the $S_{1}$ and $S_{2}$ voltage stresses are $U_{\mathrm{H}} / 2$, the voltage of the two-point of $\mathrm{AB}$ is $U_{\mathrm{AB}}=0$, the voltage of the inductance $L_{1}$ is $U_{\mathrm{L}}$, and $i_{\mathrm{L}}$ flows to high voltage side and linearly increase, as shown in Equation (2).

4. Mode $M_{2}=10, S_{2}$ and $S_{4}$ are turned off, $S_{1}$ and $S_{3}$ are turned on, the $S_{2}$ and $S_{4}$ voltage stresses are $U_{\mathrm{H}} / 2$, flying capacitor $C_{\mathrm{f} 1}$ is discharged, $U_{\mathrm{AB}}=U_{\mathrm{H}}-U_{\mathrm{f} 1}=U_{\mathrm{H}} / 2$, the voltage across inductor $L_{1}$ is $U_{\mathrm{L}}-U_{\mathrm{AB}}<0$, and $i_{\mathrm{L}}$ flows to the high-pressure side and decreases linearly. The column differential equation can be obtained as:

$$
\left\{\begin{array}{l}
\dot{i}_{\mathrm{L}}=-\frac{r_{\mathrm{L}}}{L_{1}} i_{\mathrm{L}}+\frac{1}{L} U_{\mathrm{L}}+\frac{1}{L} U_{\mathrm{f}}-\frac{1}{L} U_{\mathrm{H}} \\
\dot{U}_{\mathrm{H}}=\frac{1}{C_{\mathrm{H}}} i_{\mathrm{L}}-\frac{1}{R_{\mathrm{H}} C_{\mathrm{H}}} U_{\mathrm{H}} \\
\dot{U}_{\mathrm{f}}=-\frac{1}{C_{\mathrm{f}}} i_{\mathrm{L}}
\end{array} .\right.
$$

According to the duty cycle definition, each equation group for the modal action time can be listed during the switching period:

$$
\left\{\begin{array} { l } 
{ t _ { 1 } + t _ { 2 } + t _ { 3 } = D \mathrm { T } _ { \mathrm { s } } } \\
{ t _ { 1 } + t _ { 3 } + t _ { 4 } = D \mathrm { T } _ { \mathrm { s } } } \\
{ t _ { 1 } + t _ { 2 } + t _ { 3 } + t _ { 4 } = \mathrm { T } _ { \mathrm { s } } }
\end{array} \Rightarrow \left\{\begin{array}{l}
t_{2}=(1-D) \mathrm{T}_{\mathrm{s}} \\
t_{4}=(1-D) \mathrm{T}_{\mathrm{s}} \\
t_{1}+t_{3}=(2 D-1) \mathrm{T}_{\mathrm{s}}
\end{array} .\right.\right.
$$


The inductance satisfies the volt-second balance condition:

$$
U_{\mathrm{L}}(2 D-1) \mathrm{T}_{\mathrm{s}}+\left(U_{\mathrm{L}}-U_{\mathrm{H}} / 2\right)(2-2 D) \mathrm{T}_{\mathrm{s}}=0 \Rightarrow \frac{U_{\mathrm{H}}}{U_{\mathrm{L}}}=\frac{1}{1-D} .
$$

\subsection{Operational Modal Analysis $D<0.5$}

During the switching cycle, each arm has three modes of 00,10 , and 01.

1. Mode $M_{0}=00, S_{3}$ and $S_{4}$ are turned off, $S_{1}$ and $S_{2}$ are turned on, the voltage of $\mathrm{AB}$ is $U_{\mathrm{AB}}=$ $U_{\mathrm{H}}, S_{3}$ and $S_{4}$ voltage stress are $U_{\mathrm{H}} / 2$, the voltage of inductance $L_{1}$ is $U_{\mathrm{L}}-U_{\mathrm{H}}, i_{\mathrm{L}}$ flows to the high-voltage side and decreases linearly, and the corresponding differential equation can be expressed as:

$$
\left\{\begin{array}{l}
\dot{i}_{\mathrm{L}}=-\frac{r_{\mathrm{L}}}{L} i_{\mathrm{L}}+\frac{1}{L}\left(U_{\mathrm{L}}-U_{\mathrm{H}}\right) \\
\dot{U}_{\mathrm{H}}=-\frac{1}{R_{\mathrm{H}} C_{\mathrm{H}}} U_{\mathrm{H}} \\
\dot{U}_{\mathrm{f}}=0
\end{array} .\right.
$$

2. Mode $M_{2}=10, S_{2}$ and $S_{4}$ are turned off, $S_{1}$ and $S_{3}$ are turned on, $S_{2}$ and $S_{4}$ voltage stress are $U_{\mathrm{H}} / 2$, $C_{\mathrm{f} 1}$ is discharging, $U_{\mathrm{AB}}=U_{\mathrm{H}}-U_{\mathrm{f} 1}=U_{\mathrm{H}} / 2$, the voltage across inductor $L_{1}$ is $U_{\mathrm{L}}-U_{\mathrm{AB}}>0, i_{\mathrm{L}}$ flows to the high-voltage side and increases linearly, and the differential equation can be expressed as Equation (4).

3. Mode $M_{0}=00, S_{3}$ and $S_{4}$ are turned off, $S_{1}$ and $S_{2}$ are turned on, the voltage of $\mathrm{AB}$ is $U_{\mathrm{AB}}=U_{\mathrm{H}}$, $S_{3}$ and $S_{4}$ voltage stress are $U_{\mathrm{H}} / 2$, inductance $L_{1}$ voltage is $U_{\mathrm{L}}-U_{\mathrm{H}}, i_{\mathrm{L}}$ flow to high voltage side and the linearity is reduced, and the differential equation can be expressed as Equation (7).

4. Mode $M_{1}=01, S_{1}$ and $S_{3}$ are turned off, $S_{2}$ and $S_{4}$ are turned on, $S_{1}$ and $S_{3}$ voltage stresses are $U_{\mathrm{H}} / 2$, flying capacitor $C_{\mathrm{f} 1}$ is charging, $U_{\mathrm{AB}}=U_{\mathrm{f} 1}=U_{\mathrm{H}} / 2$, the inductor voltage across $L_{1}$ is $U_{\mathrm{L}}-$ $U_{\mathrm{AB}}>0, i_{\mathrm{L}}$ flows to the high-voltage side and increases linearly, and the differential equation can be expressed as Equation (3). According to the duty cycle definition, each mode action time can be expressed as:

$$
\left\{\begin{array}{c}
t_{2}=D \mathrm{~T}_{\mathrm{s}} \\
t_{4}=D \mathrm{~T}_{\mathrm{s}} \\
t_{1}+t_{3}=(1-2 D) \mathrm{T}_{\mathrm{s}}
\end{array} .\right.
$$

The inductance satisfies the volt-second balance:

$$
2 D \mathrm{~T}_{\mathrm{s}}\left(U_{\mathrm{L}}-U_{\mathrm{H}} / 2\right)+(1-2 D) \mathrm{T}_{\mathrm{s}}\left(U_{\mathrm{L}}-U_{\mathrm{H}}\right)=0 \Rightarrow \frac{U_{\mathrm{H}}}{U_{\mathrm{L}}}=\frac{1}{1-D} .
$$

\section{Multiple Modulation Technique}

\subsection{Two Arms Interleaved Parallel Modulation}

Two arms are paralleled, as shown in in Figure $1 \mathrm{~b}$, to increase the overcurrent capability and reduce the input side ripple. Arm 1 is composed of $S_{1}-S_{4}$, the inductor $L_{1}$ and the flying capacitor $C_{\mathrm{f} 1}$; and arm 2 is composed of $S_{5}, S_{6}, S_{7}, S_{8}$, the inductor $L_{2}$ and the flying capacitor $C_{\mathrm{f} 2}$. Among them, $S_{1}$ and $S_{4}$ are turned on complementarily, $S_{2}$ and $S_{3}$ are turned on complementarily, the modulated waves of $S_{1}$ and $S_{2}$ are interleaved $180^{\circ}$, and the $S_{3}$ and $S_{4}$ modulated waves are interleaved $180^{\circ}$, as shown in Figure 3. Arm 2 is modulated in the same manner as arm 1 with a phase lag of $90^{\circ}$.

Two arms are interleaved $90^{\circ}$ in parallel; eight modes are used at $0.5<D<0.75$, and other eight modes are used at $0.25<D<0.5$. The working mode of the space ratio is shown in Table 1 . In the forward power flow (Boost mode), the inductor currents $i_{\mathrm{L} 1}$ and $i_{\mathrm{L} 2}$ are positive and flow from the low voltage side to the high voltage side. When the negative power flows (Buck mode), the inductor currents of $i_{\mathrm{L} 1}$ and $i_{\mathrm{L} 2}$ are negative, and the high voltage side flows to the low voltage side. The driving signal between the two arms is interleaved $90^{\circ}$, and the other side bridge arm switch maintains the 
original state when one side bridge arm is operated. After the inductor current is superimposed, the low-voltage side current is $i_{\mathrm{L}}=i_{\mathrm{L} 1}+i_{\mathrm{L} 2}$ doubling the pulsation frequency, and the ripple of the $i_{\mathrm{L}}$ is reduced.

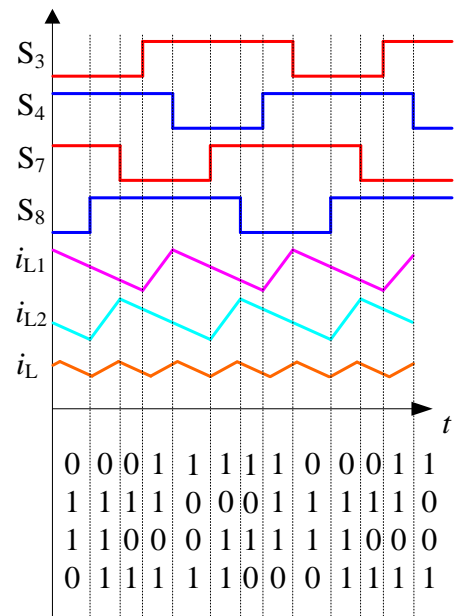

(a) $0.5<D<0.75$

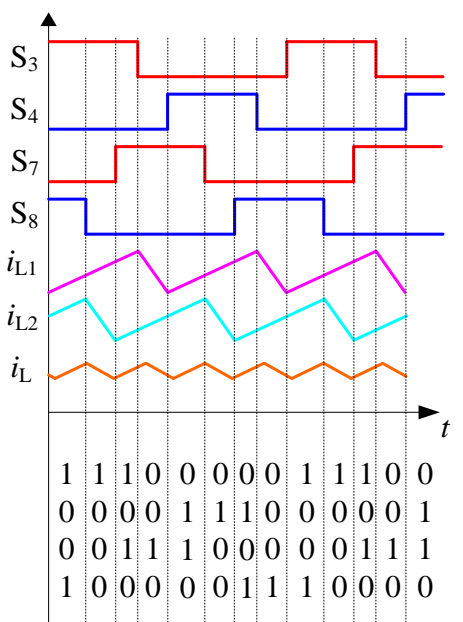

(b) $0.25<D<0.5$

Figure 3. The main waveform of two parallel arms. (a) Mode $0.5<D<0.75$, (b) Mode $0.25<D<0.5$.

Table 1. Two arms interleaved parallel coding.

\begin{tabular}{ccccccc}
\hline $\mathbf{0 ~ 0 . 2 5}$ & $\mathbf{D}=\mathbf{0 . 2 5}$ & $\mathbf{0 . 2 5} \mathbf{0 . 5}$ & $\mathbf{D}=\mathbf{0 . 5}$ & $\mathbf{0 . 5} \mathbf{0 . 7 5}$ & $\mathbf{D = 0 . 7 5}$ & $\mathbf{0 . 7 5} \mathbf{1}$ \\
\hline 0000 & 0010 & 1010 & 1010 & 0101 & 1101 & 1111 \\
0010 & 0010 & 0010 & 1010 & 1101 & 1101 & 1101 \\
0000 & 0100 & 0110 & 0110 & 1001 & 1011 & 1111 \\
0100 & 0100 & 0100 & 0110 & 1011 & 1011 & 1011 \\
0000 & 0001 & 0101 & 0101 & 1010 & 1110 & 1111 \\
0001 & 0001 & 0001 & 0101 & 1110 & 1110 & 1110 \\
0000 & 1000 & 1001 & 1001 & 0110 & 0111 & 1111 \\
1000 & 1000 & 1000 & 1001 & 0111 & 0111 & 0111 \\
\hline
\end{tabular}

Then the inductor current is superimposed, the low-voltage side current is $i_{\mathrm{L}}=i_{\mathrm{L} 1}+i_{\mathrm{L} 2}$ doubling the pulsation frequency, and the ripple of the $i_{\mathrm{L}}$ is reduced. According to Equations (2)-(9), the ripple current of three-level bi-directional DC/DC(3L-BDC) in Figure 1b, $\Delta I_{\mathrm{L} 1 \_3 \mathrm{~L} \_L B D C}$, can be calculated as

$$
\Delta I_{\mathrm{L} 1 \_3 \mathrm{~L} \_\mathrm{BDC}}=\left\{\begin{array}{ll}
\frac{\left(U_{\mathrm{H}}-2 U_{\mathrm{L}}\right)(1-D)}{2 L_{1} f_{\mathrm{s}}}, & (D>0.5) \\
\frac{\left(2 U_{\mathrm{L}}-U_{\mathrm{H}}\right) D}{2 L_{1} f_{\mathrm{s}}}, & (D \leq 0.5)
\end{array} .\right.
$$

Correspondingly, the ripple current of the inductor of two-level bidirectional DC/DC (2L_BDC) can be calculated as

$$
\Delta I_{\text {L1_2L_BDC }}=\frac{\left(U_{\mathrm{H}}-U_{\mathrm{L}}\right) D}{L_{1} f_{\mathrm{s}}} .
$$

To reduce currents ripple, $n$ arms can be cascaded, and the drive signals between the arms are interleaved $180^{\circ} / \mathrm{n}$. The more arms that participate in interleaved parallel connection, the more obvious the ripple reduction effect, and the more characteristic points of zero ripple appear at the same time- these zero ripple points show a uniform distribution law. The aforementioned analysis shows that the voltage stress on the switches and the flying capacitors of the $3 \mathrm{~L} \_\mathrm{BDC}$ is half of $U_{\mathrm{H}}$, which is just half of the traditional 2L_BDC. To reduce the voltage stress, it is necessary to employ a series connection. 


\subsection{Two Arms Complementary Series Modulation}

The topology is connected in series with two inductors to reduce the inductor current ripple amplitude; the low voltage side is isolated from the output side by two inductors, which can improve the energy storage unit safety; the series structure can reduce the voltage stress of the switches and increase the voltage level of the DBC, as shown in Figure 1c. The inductor current waveform during complementary modulation is shown in Figure $4 . S_{4}$ and $Q_{1}$ are the same drive signal, $S_{3}$ and $Q_{2}$ are the same drive signal, $S_{2}$ and $Q_{3}$ are the same drive signal, and $S_{1}$ and $Q_{4}$ are the same drive signal; that is, the switch modulation is based on the topology. The switching period inductance fluctuation frequency is equal to twice of the switching frequency, the inductance fluctuation amplitude is half of that of the single submodule, and the remaining mode complementary series modulation is shown in Table 2.

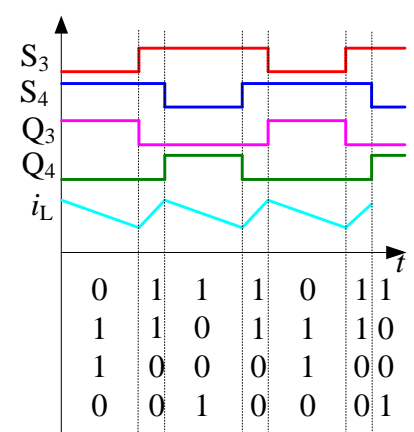

(a) $0.5<D<0.75$

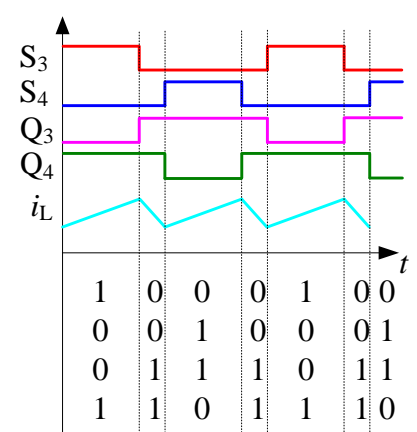

(b) $0.25<D<0.5$

Figure 4. The key waveform of two arms series. (a) Mode $0.5<D<0.75$, (b) Mode $0.25<D<0.5$.

Table 2. Two arms complementary series coding.

\begin{tabular}{ccccccc}
\hline $\mathbf{0 ~ 0 . 2 5}$ & $\mathbf{0 . 2 5}$ & $\mathbf{0 . 2 5} \mathbf{0 . 5}$ & $\mathbf{0 . 5}$ & $\mathbf{0 . 5} \mathbf{0 . 7 5}$ & $\mathbf{0 . 7 5}$ & $\mathbf{0 . 7 5} \mathbf{1}$ \\
\hline $00 / 11$ & $00 / 11$ & $00 / 11$ & $01 / 10$ & $11 / 00$ & $11 / 00$ & $11 / 00$ \\
$01 / 10$ & $01 / 10$ & $01 / 10$ & $10 / 01$ & $10 / 01$ & $10 / 01$ & $10 / 01$ \\
$00 / 11$ & $00 / 11$ & $00 / 11$ & $01 / 10$ & $11 / 00$ & $11 / 00$ & $11 / 00$ \\
$10 / 01$ & $10 / 01$ & $10 / 01$ & $10 / 01$ & $01 / 10$ & $01 / 10$ & $01 / 10$ \\
\hline
\end{tabular}

The voltage stress on the switches and the flying capacitors is $0.25 U_{\mathrm{H}}$ in Figure $1 \mathrm{c}$. In order to reduce the voltage and current stress, it is necessary to increase the series and parallel bridge arms simultaneously. The ripple current of $L_{1}$ in Figure $1 \mathrm{c}, \Delta I_{\mathrm{L} 1 \_3 \mathrm{~L} \_ \text {LBDC, }}$ can be calculated as

$$
\Delta I_{\mathrm{L} 1 \_3 \mathrm{~L} \_\mathrm{BDC}}=\left\{\begin{array}{ll}
\frac{\left(U_{\mathrm{H}}-2 U_{\mathrm{L}}\right)(1-D)}{2\left(L_{1}+L_{3}\right) f_{\mathrm{s}}}, & (D>0.5) \\
\frac{\left(2 U_{\mathrm{L}}-U_{\mathrm{H}}\right) D}{2\left(L_{1}+L_{3}\right) f_{\mathrm{s}}}, & (D \leq 0.5)
\end{array} .\right.
$$

\subsection{Four Arms Mixed Modulation}

To meet the large-capacity requirements in the bipolar DC bus, the voltage and current stress of the switching tube should be reduced, so a four-arms mixed converter is proposed, that is, the cascaded form of the interleaved parallel flying-capacitor type three-level converter, as shown in Figure $1 \mathrm{~d}$. The left and right parallel arms are interleaved $90^{\circ}$ parallel modulation, and the upper and lower series arms are complementarily connected in series. For example, when $0.5<D<0.75$, in mode $0101 / 1010$, it means $S_{3}$ is off, $S_{4}$ is on, $S_{7}$ is off, $S_{8}$ is on; while, $Q_{3}$ is on, $Q_{4}$ is off, $Q_{7}$ is on, and $Q_{8}$ is off. The modulation rule of the BDC is shown in Figure 5. 


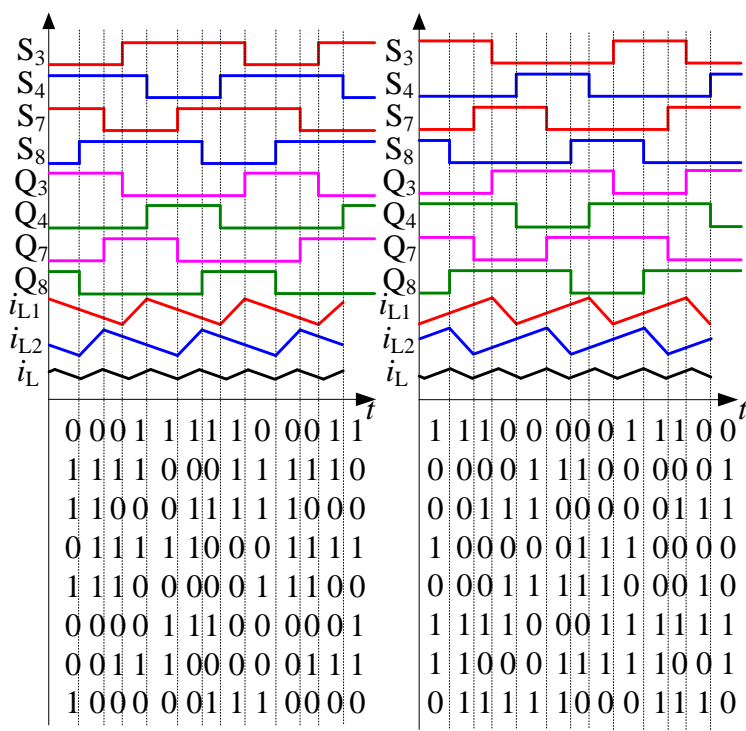

(a) $0.5<D<0.75$

(b) $0.25<D<0.5$

Figure 5. The key waveform of the four arms mixed. (a) Mode $0.5<D<0.75$, (b) Mode $0.25<D<0.5$.

By mixed modulation, the average inductor current is only half of the single-arm current, the ripple frequency is doubled, the flying capacitor voltage is $0.25 U_{\mathrm{H}}$, and the voltage stress of the switch is only $0.25 U_{\mathrm{H}}$ compared to the $2 \mathrm{~L} \_B D C$. The modulation is shown in Table 3. To compare the characteristics of the structure, shown in Figure 1, the voltage and current stress conditions are listed in Table 3, and the four arms mixed modulation is more suitable for bipolar high-power applications. This modulation strategy helps to control and protect the design of the circuit. A topological comparison of the proposed BDC in this paper with others are shown in Table 4.

Table 3. Four arms mixed modulation coding.

\begin{tabular}{ccccccc}
\hline $\mathbf{0 ~ 0 . 2 5}$ & $\boldsymbol{D = 0 . 2 5}$ & $\mathbf{0 . 2 5} \mathbf{0 . 5}$ & $\mathbf{D = 0 . 5}$ & $\mathbf{0 . 5} \mathbf{0 . 7 5}$ & $\mathbf{D = 0 . 7 5}$ & $\mathbf{0 . 7 5 ~ \mathbf { 1 }}$ \\
\hline $0000 / 1111$ & $0010 / 1101$ & $1010 / 0101$ & $1010 / 0101$ & $0101 / 1010$ & $1101 / 0010$ & $1111 / 0000$ \\
$0010 / 1101$ & $0010 / 1101$ & $0010 / 1101$ & $1010 / 0101$ & $1101 / 0010$ & $1101 / 0010$ & $1101 / 0010$ \\
$0000 / 1111$ & $0100 / 1011$ & $0110 / 1001$ & $0110 / 1001$ & $1001 / 0110$ & $1011 / 0100$ & $1111 / 0000$ \\
$0100 / 1011$ & $0100 / 1011$ & $0100 / 1011$ & $0110 / 1001$ & $1011 / 0100$ & $1011 / 0100$ & $1011 / 0100$ \\
$0000 / 1111$ & $0001 / 1110$ & $0101 / 1010$ & $0101 / 1010$ & $1010 / 0101$ & $1110 / 0001$ & $1111 / 0000$ \\
$0001 / 1110$ & $0001 / 1110$ & $0001 / 1110$ & $0101 / 1010$ & $1110 / 0001$ & $1110 / 0001$ & $1110 / 0001$ \\
$0000 / 1111$ & $1000 / 0111$ & $1001 / 0110$ & $1001 / 0110$ & $0110 / 1001$ & $0111 / 1000$ & $1111 / 0000$ \\
$1000 / 0111$ & $1000 / 0111$ & $1000 / 0111$ & $1001 / 0110$ & $0111 / 1000$ & $0111 / 1000$ & $0111 / 1000$ \\
\hline
\end{tabular}

\section{Controller design}

Define the state variable as $x=\left[i_{\mathrm{L}}, U_{\mathrm{H}}, U_{\mathrm{f}}\right]^{\mathrm{T}}$, the input variable as $u=U_{\mathrm{L}}$, the transfer function as $G_{\mathrm{id}}(\mathrm{s})$ from the duty cycle $d$ to the inductor current $i_{\mathrm{L}}$ and the transfer function $G_{\mathrm{ud}}(\mathrm{s})$ from the duty cycle $d$ to the output voltage $U_{\mathrm{H}}$, according to Equations (2)-(9).

$$
\begin{aligned}
G_{\mathrm{id}}(s) & =\frac{\frac{U_{\mathrm{L}} C_{\mathrm{H}} R_{\mathrm{H}}}{1-D}+\frac{2 U_{\mathrm{L}}}{1-D}}{C_{\mathrm{H}} L R_{\mathrm{H}} s^{2}+L s+R_{\mathrm{H}}(1-D)^{2}+r_{\mathrm{L}}}, \\
G_{\mathrm{ud}}(s) & =\frac{-\frac{L U_{\mathrm{L}}}{(1-D)^{2}} s+R_{\mathrm{H}} U_{\mathrm{L}}-\frac{r_{\mathrm{L}} U_{\mathrm{L}}}{(1-D)^{2}}}{C_{\mathrm{H}} L R_{\mathrm{H}} s^{2}+L s+R_{\mathrm{H}}(1-D)^{2}+r_{\mathrm{L}}},
\end{aligned}
$$

where, $R_{\mathrm{H}}$ is $R_{\text {load, }}$, and $r_{\mathrm{L}}$ is the inductance parasitic resistance. 
The main circuit parameters of the converter are shown in Table 5. Due to the inconsistent impedance of the IGBT parasitic parameters and the inductor winding process, the main loop has a certain degree of impedance difference. The controller's PI regulator is $G_{\mathrm{C}}(\mathrm{s})=k_{1}+k_{2} / \mathrm{s}$, where $k_{1}=0.1$, $k_{2}=50$, and the control block diagram is shown in Figure 6.

Table 4. Topological comparison.

\begin{tabular}{|c|c|c|c|c|c|}
\hline \multicolumn{6}{|c|}{$\begin{array}{l}\text { (a) Comparison in terms of passive component and out gain, inductor ripple current and switching } \\
\text { frequency. }\end{array}$} \\
\hline Proposed & $\begin{array}{l}\text { Number of } \\
\text { Elements }\end{array}$ & Gain of Voltage & $\Delta i_{\mathrm{L}}$ & & $f_{\Delta i_{\mathrm{L}}}$ \\
\hline SC [23] & $C=3 S=4 L=1$ & $\frac{2 U_{\mathrm{L}}}{1-D}$ & $\frac{\left(U_{\mathrm{H}}-2 U_{\mathrm{L}}\right) D}{2 L f_{\mathrm{s}}}$ & & $f_{\mathrm{s}}$ \\
\hline Double Buck/Boost [24] & $C=3 S=4 L=2$ & $\frac{U_{\mathrm{L}}}{1-D}$ & & & $2 f_{\mathrm{s}}$ \\
\hline Basic FC [5] & $C=3 S=4 L=1$ & $\frac{U_{\mathrm{L}}}{1-D}$ & $\begin{array}{l}\frac{\left(U_{\mathrm{H}}-2 U_{\mathrm{L}}\right)(1-D)}{2 L_{1} f_{\mathrm{s}}}, \\
\frac{\left(2 U_{\mathrm{L}}-U_{\mathrm{H}}\right) D}{2 L_{1} f_{\mathrm{s}}},\end{array}$ & $\begin{array}{l}(D>0.5) \\
(D \leq 0.5)\end{array}$ & $2 f_{\mathrm{s}}$ \\
\hline Interleaved FC [7] & $C=4 S=8 L=2$ & $\frac{U_{\mathrm{L}}}{1-D}$ & $\begin{array}{l}\frac{\left(U_{\mathrm{H}}-2 U_{\mathrm{L}}\right)(1-D)}{2 L_{1} f_{\mathrm{s}}} \\
\frac{\left(2 U_{\mathrm{L}}-U_{\mathrm{H}}\right) D}{2 L_{1} f_{\mathrm{s}}},\end{array}$ & $\begin{array}{l}(D>0.5) \\
(D \leq 0.5)\end{array}$ & $4 f_{\mathrm{s}}$ \\
\hline Complementary FC [21] & $C=5 S=8 L=2$ & $\frac{U_{\mathrm{L}}}{1-D}$ & $\begin{array}{l}\frac{\left(U_{\mathrm{H}}-2 U_{\mathrm{L}}\right)(1-D)}{2\left(L_{1}+L_{3}\right) f_{\mathrm{s}}} \\
\frac{\left(2 U_{\mathrm{L}}-U_{\mathrm{H}}\right) D}{2\left(L_{1}+L_{3}\right) f_{\mathrm{s}}}\end{array}$ & $\begin{array}{l}(D>0.5) \\
(D \leq 0.5)\end{array}$ & $2 f_{\mathrm{s}}$ \\
\hline This paper & $C=7 S=16 L=4$ & $\frac{U_{\mathrm{L}}}{1-D}$ & $\begin{array}{l}\frac{\left(U_{\mathrm{H}}-2 U_{\mathrm{L}}\right)(1-D)}{2\left(L_{1}+L_{3}\right) f_{\mathrm{s}}} \\
\frac{\left(2 U_{\mathrm{L}}-U_{\mathrm{H}}\right) D}{2\left(L_{1}+L_{3}\right) f_{\mathrm{s}}}\end{array}$ & $\begin{array}{l}(D>0.5) \\
(D \leq 0.5)\end{array}$ & $4 f_{\mathrm{s}}$ \\
\hline
\end{tabular}

(b) Comparison in terms of out capacitor, flying capacitor voltage, voltage across switch, inductor current and fault tolerant capabilities

\begin{tabular}{cccccc}
\hline Proposed. & $\begin{array}{c}\text { Output Capacitor } \\
\text { Voltage }\end{array}$ & $\begin{array}{c}\text { Flying capacitor } \\
\text { voltage }\end{array}$ & $\begin{array}{c}\text { Switch } \\
\text { Voltage }\end{array}$ & $\begin{array}{c}\text { Inductor } \\
\text { Current }\end{array}$ & $\begin{array}{c}\text { Fault } \\
\text { Tolerance }\end{array}$ \\
\hline SC [23] & $2 U_{\mathrm{L}} /(1-D)$ & $0.5 U_{\mathrm{H}}$ & $0.5 U_{\mathrm{H}}$ & $I_{\mathrm{L}}$ & Weak \\
Double Buck/Boost [24] & $U_{\mathrm{L}} /(1-D)$ & $N o$ & $0.5 U_{\mathrm{H}}$ & $I_{\mathrm{L}}$ & Weak \\
Basic FC [5] & $U_{\mathrm{L}} /(1-D)$ & $0.5 U_{\mathrm{H}}$ & $0.5 U_{\mathrm{H}}$ & $I_{\mathrm{L}}$ & Weak \\
Interleaved FC [7] & $U_{\mathrm{L}} /(1-D)$ & $0.5 U_{\mathrm{H}}$ & $0.5 U_{\mathrm{H}}$ & $0.5 I_{\mathrm{L}}$ & Average \\
Complementary FC [21] & $U_{\mathrm{L}} /(2-2 D)$ & $0.25 U_{\mathrm{H}}$ & $0.25 U_{\mathrm{H}}$ & $I_{\mathrm{L}}$ & Average \\
This paper & $U L /(2-2 D)$ & $0.25 U_{\mathrm{H}}$ & $0.25 U_{\mathrm{H}}$ & $0.5 I_{\mathrm{L}}$ & Strong \\
\hline
\end{tabular}

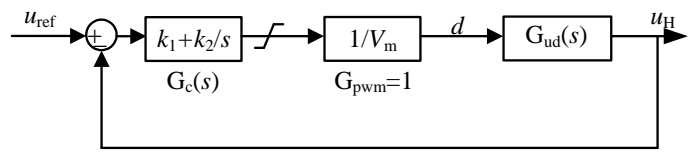

(a) Single voltage loop

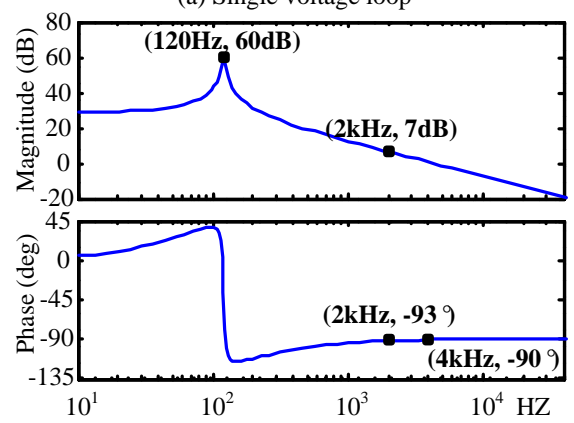

(c) Without current loop control

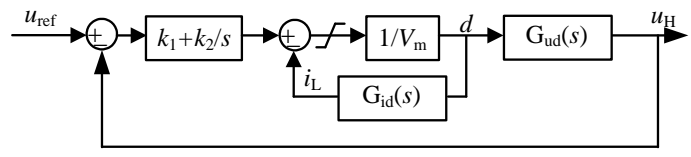

(b) Double voltage and current loop

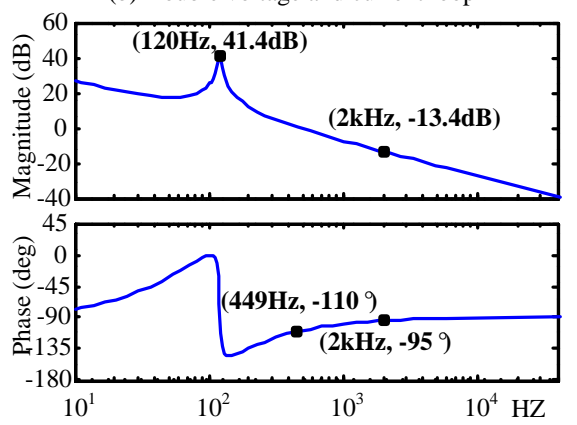

(d) With current loop control

Figure 6. The control strategy. (a) \& (c) are single voltage loop and its Bode without current loop control. (b) \& (d) are double voltage-current loop and its Bode with current loop control.

The Bode diagram of the proposed control strategy by a single voltage loop, as shown in Figure 6c. The low frequency range is $30 \mathrm{~dB}$, the high frequency band traverses $0 \mathrm{~dB}$ with a slope of $-20 \mathrm{~dB} / \mathrm{dec}$, and the corner frequency is $120 \mathrm{~Hz}$. The gain crossover frequency is $4 \mathrm{kHz}$, the phase margin is $90^{\circ}$, 
and the system is stable; however, the gain is higher than $0 \mathrm{~dB}$ at 0.1 times of switching frequency. The current inner loop uses inductor current feedback, as shown in Figure 6d. The PI regulator is $G_{c}(s)=0.1+50 / s$, the crossing frequency of the open-loop transfer function is $449 \mathrm{~Hz}$ when crossing the $0 \mathrm{~dB}$ line, and the phase margin is $70^{\circ}$ at the crossing frequency. It can be judged that the closed loop system is stable. A first-order low-pass filter is added to the loop due to the influence of high frequency noise. The cutoff frequency of the first-order low-pass filter $\left(\omega_{\mathrm{c}}=2 \pi \mathrm{fc}\right)$ is set at 0.1 times the switching frequency, and the gain margin $\mathrm{kg}\left(f_{\mathrm{c}}=2 \mathrm{kHz}\right)$ is $13.4 \mathrm{~dB}$, which is ideal. The pole introduced by the first-order LPF is far from the real axis, and has little effect on the bode diagram and can be ignored.

Table 5. The Parameters of BDC.

\begin{tabular}{cccc}
\hline Parameters & Value & Parameters & Value \\
\hline$U_{\mathrm{L}} / \mathrm{V}$ & $150 \sim 220$ & $C_{\mathrm{L}} / \mu \mathrm{F}$ & 220 \\
$U_{\mathrm{H}} / \mathrm{V}$ & 400 & $C_{\mathrm{H}} / \mu \mathrm{F}$ & 110 \\
$P_{\mathrm{o}} / \mathrm{kW}$ & 1 & $C_{\mathrm{f} 1} / \mu \mathrm{F}$ & 110 \\
$L_{1} \sim L_{2} / \mathrm{mH}$ & 2 & $C_{\mathrm{f} 2} / \mu \mathrm{F}$ & 110 \\
$r_{\mathrm{L}} / \Omega$ & 0.2 & $f_{\mathrm{s}} / \mathrm{kHz}$ & 20 \\
\hline
\end{tabular}

\section{Experimental result}

The experimental platform is shown in Figure 7. In the platform, the DC power supply E and resistance $R$ are used to simulate the power generation change of the renewable energy source. The rated voltage of the DC power supply $E$ is $450 \mathrm{~V}$, and the DC bus voltage rating is $400 \mathrm{~V}$. Super capacitor rated voltage is $250 \mathrm{~V}$, rated capacity is $10 \mathrm{~F}$, maximum discharge current is $15 \mathrm{~A}$, charging current is $10 \mathrm{~A}$, super capacitor voltage $U_{\mathrm{L}}$ range is $150 \sim 220 \mathrm{~V}$; switching frequency $f_{\mathrm{s}}$ is $20 \mathrm{kHz}$. DC power supply Chroma 62050H-600 (Chroma Systems Solutions, Inc., Foothill Ranch, CA, USA), DC probe YOKOGAWA 701934 (Yokogawa Electric, Inc., Tokyo, Japan), oscilloscope Tek DPO2024B (Tektronix, Inc., Beaverton, OR, USA). The control chip uses DSP (TMS28335) combined with FPGA (EP3C25Q240); DSP is used for signal sampling and control signal generation, and FPGA is used to generate the modulated wave. To test the feasibility of multiple applications, super capacitor $U_{\mathrm{L}}=$ $200 \mathrm{~V}$, high side load $R_{\mathrm{H}}=200 \Omega$, adjustable power supply $E=450 \mathrm{~V}$, resistance $R=10 \Omega$; during switch $S$ disconnection, super capacitor discharge, converter operates on boost $0.5<D<0.75$ mode, the high side capacitor voltage is stable to $U_{\mathrm{H}}=400 \mathrm{~V}$. Super capacitor $U_{\mathrm{L}}=250 \mathrm{~V}$, high-voltage-side load $R_{\mathrm{H}}=200 \Omega$, adjustable power supply $E=450 \mathrm{~V}$, resistance $R=10 \Omega$; during switch $S$ closing, super capacitor charging.

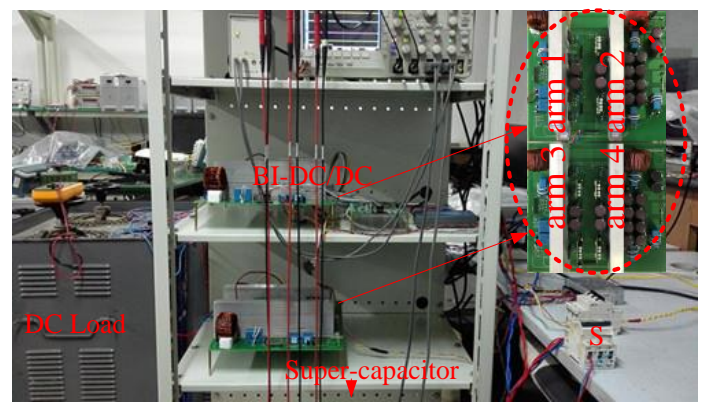

(a) System photo

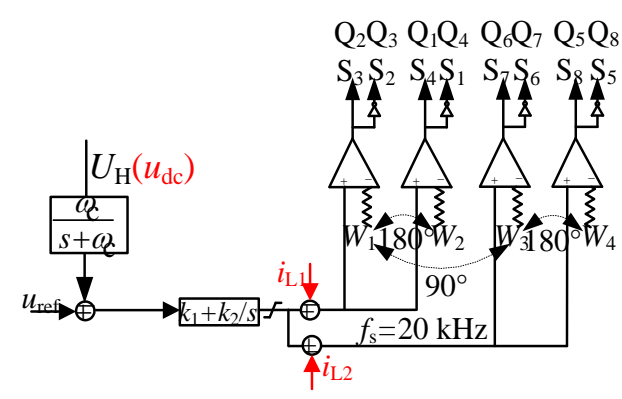

(b) Control System

Figure 7. Experimental setup. (a) The experimental system, (b) Control system logic.

In the project, due to the inconsistent IGBT parasitic parameters and the inconsistent impedance caused by the inductor winding process, the main loop objectively has impedance differences.

The voltage and current double closed-loop PI regulators are used for impedance matching. The two control loops share the voltage outer loop, and the current inner loop uses respective inductor 
current feedback. The control loop is shown in Figure $7 \mathrm{~b}$. The difference in the modulation signals generated by the control loop adjusts the respective output impedances to achieve current sharing control. The left and right arms are interleaved $90^{\circ}$ parallel, the two inductor current ripples cancel each other, and the output voltage is stable, as shown in Figures 8 and 9 . The current $i_{\mathrm{L}}$ fluctuating frequency is twice of the switching frequency, and the inductor current fluctuation amplitude is reduced, due to $i_{\mathrm{L}}$ through two inductors evenly. Two arms series, the flying capacitor voltage is $0.25 U_{\mathrm{H}}$, as shown in Figure 10. The inductor current ripple is small, and the flying capacitor voltage is equal to $0.25 U_{\mathrm{H}}$.

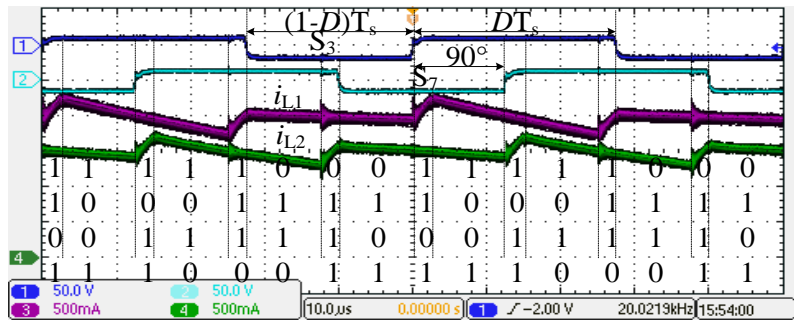

(a) Boost mode without circumferential inhibition

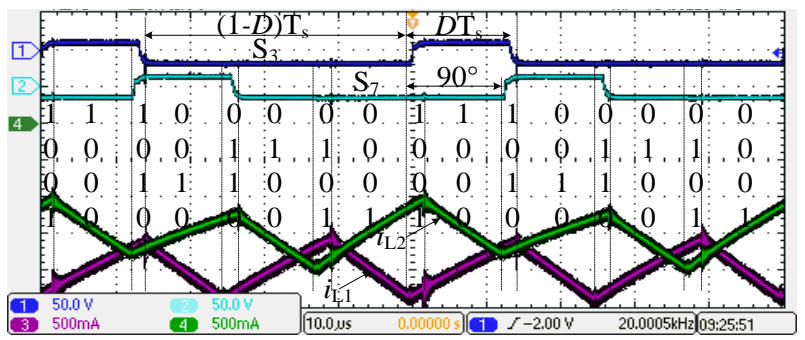

(b) Buck mode without circumferential inhibition

Figure 8. Left and right arms interleaved $90^{\circ}$ parallel without circumferential inhibition. (a) Boost mode. (b) Buck mode.

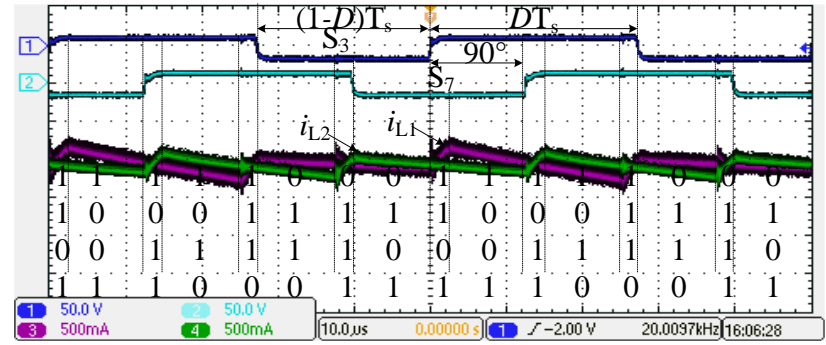

(a) Boost mode with circumferential inhibition

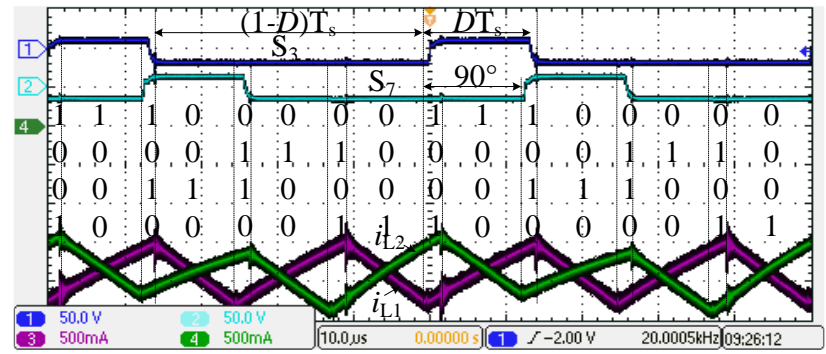

(b) Buck mode with circumferential inhibition

Figure 9. Left and right arms interleaved $90^{\circ}$ parallel with circumferential inhibition. (a) Boost mode, (b) Buck mode.

Switch $S$ is turned on at $t_{\mathrm{ON}}$, and the supercapacitor charging power is $800 \mathrm{~W}$ in buck mode. Switch $S$ is turned off at $t_{\mathrm{OFF}}$, and the supercapacitor discharging power is $1200 \mathrm{~W}$ in boost mode, as shown in Figure 11. The dynamic response time is less than $20 \mathrm{~ms}$ from charging to discharging. The dynamic response time is 
$400 \mathrm{~ms}$ from discharging to charging in the four-arms mixed modes. The flying capacitor voltage is always stable, and the DC bus voltage fluctuation is less than $20 \mathrm{~V}$. The input voltage varies between 150-220 V, the output voltage is stable at $400 \mathrm{~V}$, and the change range of $D$ is $0.63-0.45$. From the experimental results in Figures $8-11$, it can be seen that the input and output side voltage ripple is less than $1 \%$, and the current ripple frequency is relatively small, which is beneficial to the stable operation of the energy storage unit. When $Q_{7}$ shorted, $i_{\mathrm{L} 4}$ ripple is only once per cycle, losing the advantage of three levels. However, the overall performance of the converter remains stable, and the input and output voltage ripples are low, as shown in Figure 12. Therefore, the BDC has a strong fault tolerance ability, and failure of any one of the arms does not affect the operation of other arms.

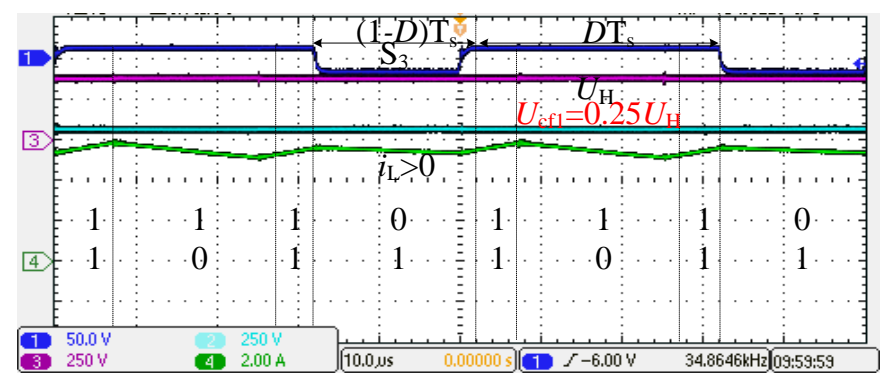

(a) Boost mode

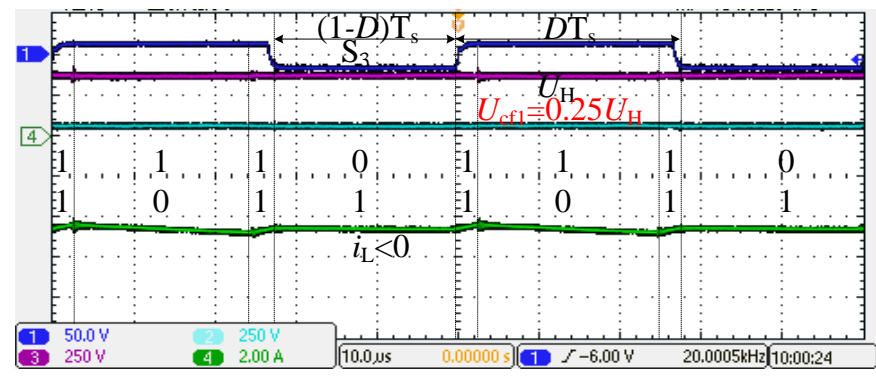

(b) Buck mode

Figure 10. Two arms complementary series. (a) Boost mode, (b) Buck mode.

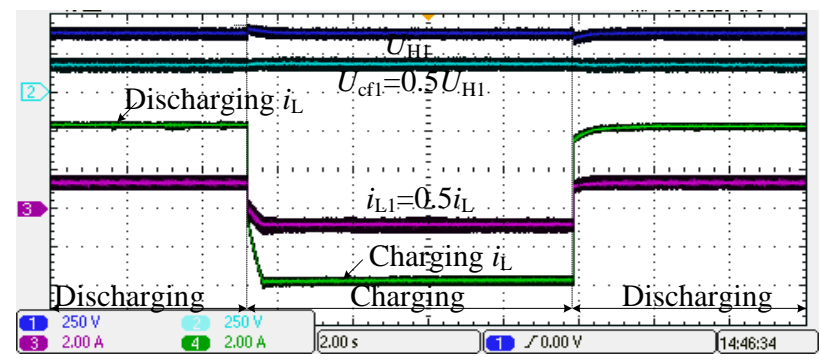

(a) Two arms parallel

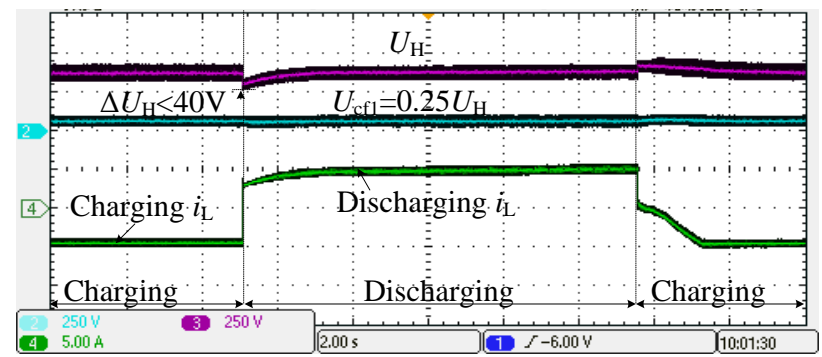

(b) Two arms series

Figure 11. Transient response for bidirectional operation. (a) Two arms interleaved parallel transient response, (b) Two arms complementary series transient response. 


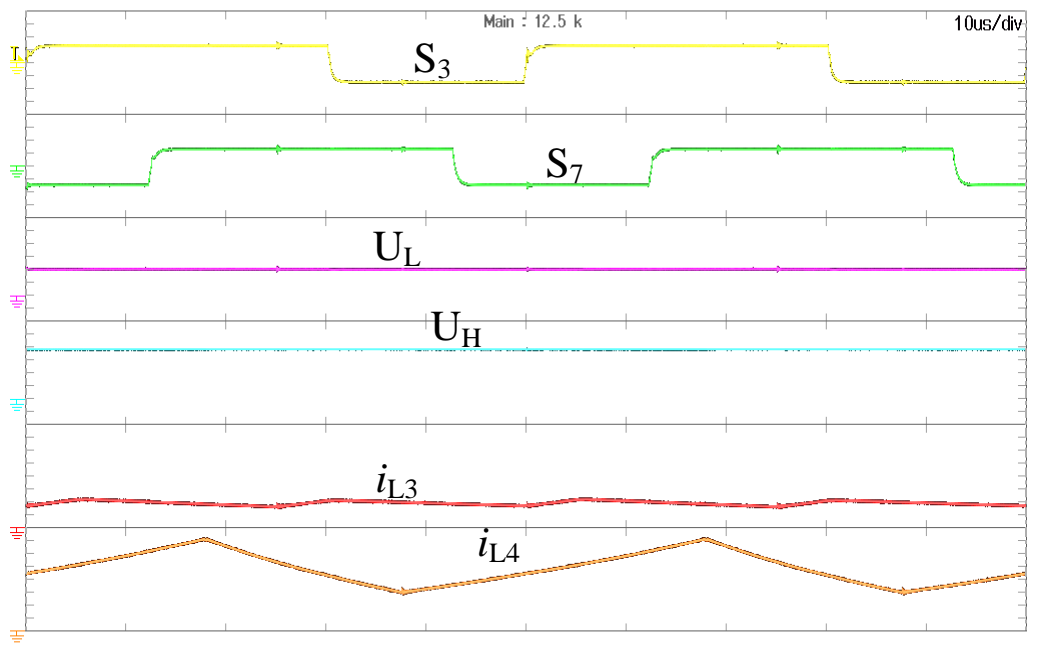

Figure 12. Switch Q7 short circuit experiment.

The efficiency is reduced, due to the inherent loss increase with a light load. Since there is a dead time of $1.5 \mu$ s when the converter is actually running, energy can be transferred from the low voltage side to the high voltage side through the IGBT body diode during dead time, as shown in Figure 13. Thus, the boost mode efficiency is higher than the buck mode. The efficiency curve is more than $90 \%$ from light load to heavy load, meeting design requirements.

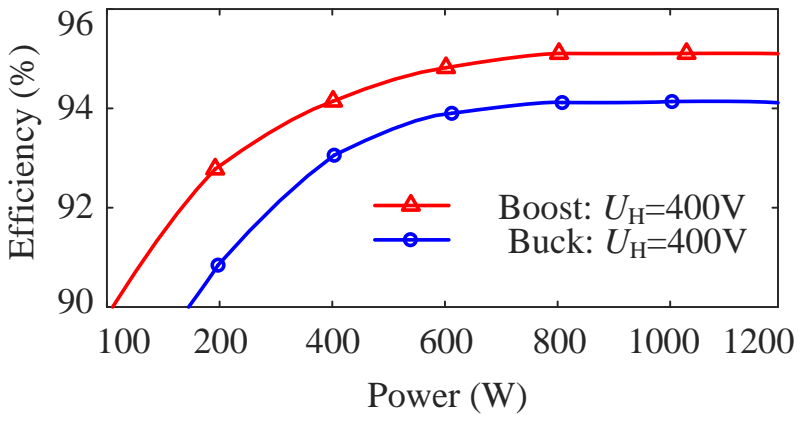

Figure 13. The efficiency curves.

\section{Conclusions}

This paper proposes a BDC topology with a multiplexed modulation strategy for high-power energy storage in bipolar DC microgrids. The parallel arms divide the input side current, which can effectively overcome the current difference caused by the inconsistent parasitic parameters of the parallel arms. The series arms divide the voltage of the high voltage side, which can effectively reduce the voltage stress of the switch and the flying capacitor. The bidirectional transient response is milliseconds, which ensures the dynamic performance and operating efficiency of the converter. The BDC has a strong fault tolerance ability, and the failure of any one of the arms does not affect the operation of other arms. The proposed BDC topology and its modulation strategy can effectively solve the issue of high-power energy storage in bipolar DC microgrids.

Author Contributions: P.L. designed the prototype and was responsible for writing the paper. C.Z., S.P. and L.Z. were responsible for guidance in the experiment and thesis writing process.

Funding: This research was supported by the National Nature Science Foundation of China under Grants 51477148 and the Science Foundation of Hebei University of Science and technology Grants PYB2019011. This research also received funding from EEEIC International, Poland.

Conflicts of Interest: The authors declare no potential conflict of interest. 


\section{References}

1. Ji, Y.; Yang, Y.; Zhou, J.; Ding, H.; Guo, X.; Padmanaban, S. Control Strategies of Mitigating Dead-time Effect on Power Converters: An Overview. Electronics 2019, 8, 196. [CrossRef]

2. Guo, X.; Jia, X. Hardware-based cascaded topology and modulation strategy with leakage current reduction for transformerless PV systems. IEEE Trans. Ind. Electron. 2016, 62, 7823-7832. [CrossRef]

3. Guo, X.; Yang, R.Y.; He, R.; Wang, B.; Blaabjerg, F. Transformerless Z-source four-leg PV inverter with leakage current reduction. IEEE Trans. Power Electron. 2019, 34, 4343-4352. [CrossRef]

4. Mahmoudi, M.A.H.; Ahmadi, R. Modulated model predictive control of three level flying capacitor buck converter. In Proceedings of the IEEE Power and Energy Conference at Illinois (PECI), Champaign, IL USA, 23-24 February 2017; pp. 1-5.

5. Jin, K.; Yang, M.; Ruan, X.; Xu, M. Three-Level Bidirectional Converter for Fuel-Cell/Battery Hybrid Power System. IEEE Trans. Ind. Electron. 2010, 57, 1976-1986. [CrossRef]

6. Zhang, C.; Li, P.; Kan, Z.; Chai, X.; Guo, X. Integrated Half Bridge CLLC Bidirectional Converter for Energy Storage Systems. IEEE Trans. Ind. Electron. 2018, 65, 3879-3889. [CrossRef]

7. Li, P.; Zhang, C.; Kan, Z.; Fu, Y. An Interleaving 90 Three-Level DC-DC Converter and Current Sharing Control. In Proceedings of the 2nd IEEE International Power Electronics and Application Conference and Exposition, Shenzhen, China, 4-7 November 2018.

8. Dragičević, T.; Guerrero, J.M.; Vasquez, J.C.; Škrlec, D. Supervisory Control of an Adaptive-Droop Regulated DC Microgrid with Battery Management Capability. IEEE Trans. Power Electron. 2014, 29, 695-706. [CrossRef]

9. Huang, X.; Lee, F.C.; Li, Q.; Du, W. High-Frequency High-Efficiency GaN-Based Interleaved CRM Bidirectional Buck/Boost Converter with Inverse Coupled Inductor. IEEE Trans. Power Electron. 2016, 31, 4343-4352. [CrossRef]

10. Xiao, G.; Zhou, J.; He, R.; Jia, X.; Rojas, C.A. Leakage current attenuation of a three-phase cascaded inverter for transformerless grid-connected pv systems. IEEE Trans. Ind. Electron. 2018, 65, 676-686.

11. Chen, W.; Ruan, X.; Yan, H.; Tse, C.K. DC/DC Conversion Systems Consisting of Multiple Converter Modules: Stability, Control, and Experimental Verifications. IEEE Trans. Power Electron. 2009, 24, 1463-1474. [CrossRef]

12. Jin, L.; Liu, B.Y.; Duan, S.X. ZVS Operation Range Analysis of Three-Level Dual Active Bridge DC-DC Converter with Phase-Shift Control. In Proceedings of the 2017 Thirty Second Annual IEEE Applied Power Electronics Conference and Exposition (Apec), Tampa, FL, USA, 26-30 March 2017.

13. Wang, Y.; Yuan, Z.; Fu, J.; Li, Y.; Zhao, Y. A feasible coordination protection strategy for MMC-MTDC systems under DC faults. Int. J. Electr. Power Energy Syst. 2017, 90, 103-111. [CrossRef]

14. Kakigano, H.; Miura, Y.; Ise, T. Low-Voltage Bipolar-Type DC Microgrid for Super High-Quality Distribution. IEEE Trans. Power Electron. 2010, 25, 3066-3075. [CrossRef]

15. Xiao, G.; Yang, Y.; Wang, B.; Blaabjerg, F. Leakage Current Reduction of Three-phase Z-source three-level four-leg inverter for transformerless PV system. IEEE Trans. Power Electron. 2019, 34, 6299-6308.

16. Dusmez, S.; Khaligh, A.; Hasanzadeh, A. A Zero-Voltage-Transition Bidirectional DC/DC Converter. IEEE Trans. Ind. Electron. 2015, 62, 3152-3162. [CrossRef]

17. Guo, Z.; Chai, X.; Li, P.; Zhang, C. A new balance control method of three-level converter NPP. In Proceedings of the IEEE 8th International Power Electronics and Motion Control Conference (IPEMC-ECCE Asia), Piscataway, NJ, USA, 22-26 May 2016; pp. 2356-2361.

18. Singh, S.N. Selection of non-isolated DC-DC converters for solar photovoltaic system. Renew. Sustain. Energy Rev. 2017, 76, 1230-1247.

19. Do, H.L. A Soft-Switching DC/DC Converter with High Voltage Gain. IEEE Trans. Power Electron. 2010, 25, $1193-1200$.

20. Zhang, X.S.; Yuan, Y.; Hua, L.; Cao, Y.; Qian, K.J. On Generation Schedule Tracking of Wind Farms with Battery Energy Storage Systems. IEEE Trans. Sustain. Energy 2017, 8, 341-353. [CrossRef]

21. Naderi, R.; Sadigh, A.K.; Smedley, K.M. Dual Flying Capacitor Active-Neutral-Point-Clamped Multilevel Converter. IEEE Trans. Power Electron. 2016, 31, 6476-6484. [CrossRef]

22. Mohammadi, F. Power Management Strategy in Multi-Terminal VSC-HVDC System. In Proceedings of the 4th National Conference on Applied Research in Electrical, Mechanical, Computer and IT Engineering, Tehran, Iran, 5 January 2018. 
23. Uno, M. High Step-Down Converter Integrating Switched Capacitor Converter and PWM Synchronous Buck Converter. In Proceedings of the 35th International Telecommunications Energy Conference, Hamburg, Germany, 13-17 October 2013.

24. Li, X.; Zhang, W.; Li, H.; Xie, R.; Xu, D. Design and control of bi-directional DC/DC converter for 30kW fuel cell power system. In Proceedings of the 8th International Conference on Power Electronics-ECCE Asia, Jeju, Korea, 30 May-3 June 2011; pp. 1024-1030. 